\title{
Endotoxin Effects on Cardiac and Renal Functions and Cardiorenal Syndromes
}

\author{
Grazia Maria Virzi ${ }^{a, b}$ Anna Clementi ${ }^{b, c}$ Alessandra Brocca ${ }^{b}$ Claudio Ronco ${ }^{a, b}$

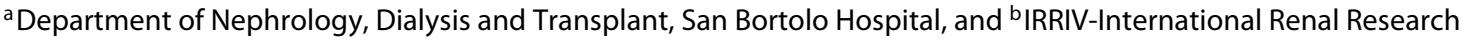 \\ Institute Vicenza, and ' Department of Nephrology and Dialysis, San Giovanni Di Dio Hospital, Agrigento, Italy
}

\section{Keywords}

Endotoxin · Lipopolysaccharide · Heart · Kidney ·

Cardiorenal syndrome $\cdot$ Sepsis

\begin{abstract}
Gram-negative sepsis is a major cause of morbidity and mortality in critical ill patients. Recent findings in molecular biology and in signaling pathways have enhanced our understanding of its pathogenesis and opened up opportunities of innovative therapeutic approaches. Endotoxin plays a pivotal role in the pathogenesis of multi-organ dysfunction in the setting of gram-negative sepsis. Indeed, heart and kidney impairments seem to be induced by the release of circulating pro-inflammatory and pro-apoptotic mediators triggered by endotoxin interaction with immune cells. These molecules are responsible for cellular apoptosis, autophagy, cell cycle arrest, and microRNAs activation. Therefore, the early identification of sepsis-associated acute kidney injury and heart dysfunction may improve the patient clinical outcome. In this report, we will consider the role of endotoxin in the pathogenesis of sepsis, its effects on both cardiac and renal functions, and the interactions between these 2 systems in the setting of cardiorenal syndromes (CRS), particularly in CRS type 5. Finally, we will discuss the possible role of extracorporeal therapies in reducing endotoxin levels.
\end{abstract}

(c) 2017 S. Karger AG, Basel

\section{Introduction}

Sepsis is a complex disorder, which is characterized by a dysregulated host response to an active infection, caused by invading microorganisms or their products [1]. Tolllike receptors (TLRs) are expressed on immune and nonimmune cells, and they are responsible for pathogen recognition [2]. Moreover, TLRs and pattern recognition receptors can amplify the inflammatory response by binding endogenous ligands, released from injured cells. This devastating response leads to an imbalance between proand anti-inflammatory mechanisms, thus predisposing an individual to the development of multiple organ dysfunction syndrome.

Gram-Negative Sepsis, Cardiorenal Syndrome Type 5 and Lipopolysaccharide

Systemic gram-negative sepsis remains one of the most severe conditions complicating the course of hospitalized subjects, mainly in critically ill patients in the intensive care unit (ICU). Despite significant progresses in critical care research and in molecular biology, the morbidity and mortality related to this clinical condition remain unacceptably elevated [3]. In gram-negative sepsis, the prime initiator is endotoxin, also known as lipopolysaccharide (LPS), which is the main component of the bacterial outer membrane [4]. The investigation of the

\section{KARGER}

(c) 2017 S. Karger AG, Basel

E-Mail karger@karger.com

www.karger.com/bpu
Dr. Grazia Maria Virzì

Department of Nephrology, Dialysis and Transplantation, San Bortolo Hospital International Renal Research Institute Vicenza

Via Rodolfi, 37, IT-36100 Vicenza (Italy)

E-Mail graziamaria.virzi@gmail.com 
function of endotoxin in the pathophysiology of sepsis has been studied since 1800s, when LPS was first revealed as a gram-negative cell wall toxin responsible for lethal shock [5]. Following its release into the bloodstream, endotoxin is specifically recognized by TLR4, which enables immune response against invading pathogens with the release of inflammatory mediators [6]. When their production becomes uncontrolled and dysregulated, septic shock develops with multiple organ dysfunction, such as myocardial depression and renal impairment [7-11], which are hallmarks of cardiorenal syndrome (CRS) type 5 in the setting of sepsis. CRS type 5 , secondary to the septic state, is characterized by a combination of direct and indirect effects of endotoxin which induces the release of a huge array of pro- and anti-inflammatory mediators, implicated in the pathogenesis of cardiac and renal dysfunctions $[12,13]$. Moreover, TLR4 activation is known to induce microRNAs (miRNA), which control and regulate the excessive inflammatory response [14]. Based on this theory, it is rational to eliminate and/or to antagonize endotoxin when treating patients with CRS type 5, secondary to sepsis $[15,16]$. This can be realized today by a very specific hemoperfusion treatment utilizing cartridges with immobilized polymyxin-B in an extracorporeal circuit, able to offer a considerable removal of LPS with improvement of clinical outcome [17].

In this report, we will investigate the role of endotoxin in the pathogenesis of sepsis, its effects on both cardiac and renal functions, and the interactions between these 2 systems in the setting of cardiorenal syndromes (CRS), particularly in CRS type 5, the role of miRNAs in TLR4 signaling, and finally the possible role of extracorporeal therapies in reducing endotoxin levels in septic patients.

\section{LPS/TLR4 Signal Pathway}

\section{Lipopolysaccharide}

LPS or endotoxin is an abundant glycolipid present on the outer membrane of gram-negative bacteria [4]. LPS consists of 3 distinct regions which differ genetically, structurally, and antigenically. The hydrophobic membrane anchor called Lipid A is responsible for the endotoxic effect of LPS, and its structure remains extremely conserved among different species [18]. The core oligosaccharide is a short chain of sugar residues with multiple phosphoryl substituents, while the $\mathrm{O}$-antigen is a serospecific polymer composed of oligosaccharide repeat units. After its release into the bloodstream, LPS promptly combines with LPS-binding protein, and this complex

Endotoxin: Cardiac and Renal Effects binds to a cluster of differentiation 14 (CD14), a highaffinity LPS receptor present on the surface of monocytes [19].

\section{Toll-Like Receptors}

The recognition of microbial pathogen-associated molecular patterns is mediated by membrane-bound host receptors, one of the most important group of which is the TLR family [19], characterized by a large, leucine-rich extracellular domain, a single transmembrane segment, and a short cytoplasmic tail. Ten different types of TLRs have been described in humans (TLR1-10). TLRs are expressed in most human tissues, in particular in organs implicated in the immune defense, such as spleen and blood, as well as in those exposed to the external environment (i.e., skin, lung, and intestines). Furthermore, the level and type of expressed TLRs depends on the type of invading pathogen [20].

In these scenarios, TLR4 is responsible for the recognition of endotoxin and induces immune activation against gram-negative bacteria. TRL4 is present on the surface of different cells, such as neutrophils, monocytes, and macrophages [6].

\section{LPS/TRL4 Activation}

The central role of TLR4 as an LPS receptor is strengthened by the observation that TLR4-deficient mice are hyporesponsive to endotoxin effects, counting for suppressed cytokine production and reduced proliferation of splenocytes [21]. Indeed, TLR4-deficient animals do not reveal typical signs of endotoxic shock following the exposure to LPS [21, 22]. Furthermore, Lakhani and Bogue [19] have reported the frequent variation in the ability of LPS from different strains of bacteria to induce the signaling through TLR4, and the capability of some bacteria to adapt their LPS to escape recognition by the innate immune system.

The signal pathway involves the interaction of LPS/ LPS-binding protein with CD14, followed by consequent events transduced through TLR4 and an adaptor molecule, myeloid differentiation 2 protein (MD-2) [23-25]. Indeed, TLR4 remains the only TLR member that does not directly connect its respective ligand and requires a co-receptor; in fact the MD-2 protein is necessary for LPS recognition and is directly implicated in the activation of the receptor complex [23]. The transfer of LPS from CD14 to MD-2, coupled with the association of MD-2 to TLR4, is mandatory for downstream signaling activation [26], which is mediated by toll/interleukin-1 receptor. 
Table 1. Small non-coding RNAs classification

Small non-coding regulatory RNAs

RNA that does not encode a protein but regulates gene expression

\begin{tabular}{ll}
\hline Shorter length RNA & Longer length RNA \\
$20-25$ nucleotides & $20-25$ nucleotides \\
- Small interfering RNAs & - Piwi-interacting RNAs \\
- MicroRNAs & \\
\hline
\end{tabular}

TLR4 is the only TLR that can transmit the activating signal by 2 distinct intracellular pathways involving both myeloid differentiation primary response gene 88 (MyD88)-dependent and MyD88-independent signaling events [27]. Both pathways result in the translocation of the mammalian transcription factor, nuclear factor $\mathrm{kB}$ (NF-kB), with subsequent upregulation of pro-inflammatory cytokines and a co-stimulatory molecule for Tcell activation [28].

\section{Role of MicroRNA in LPS/TLR4 Signaling}

\section{Small Non-Coding RNAs}

Small non-coding RNAs are constituted by about 18 30 endogenous nucleotides and represent an alternative intrinsic mechanism in gene regulation. Almost 2,500 types of these molecules have been isolated in different life forms: they have been found in all human cells and are evolutionarily well conserved. Understanding the role of these non-coding molecules, both in healthy and disease conditions, is crucial due to their possible association with many critical biological functions [29, 30].

Small non-coding RNAs regulate the expression of protein-coding genes through sequence-specific recognition, binding to $3^{\prime}$ or $5^{\prime}$-untranslated region $3^{\prime} \mathrm{UTR}$ or $5^{\prime} \mathrm{UTR}$ ) of target messenger RNA (mRNA) or promoter sequences, thus regulating mRNA levels by post-transcriptional mechanisms $[31,32]$. Partial sequence complementarity between a small non-coding RNA and its target site in a specific mRNA is often sufficient for binding [33]. Additionally, these small RNAs are released from cells and enter the bloodstream directed toward targeted cells, thus denoting a novel communication approach in cell - cell or cell - organ signal transduction. Different types of small non-coding RNA exist and they have been divided into 3 main categories: miRNAs, small interfering RNA, and piwi-interacting RNAs on the basis of their features related to the origin, structure, associated effector proteins, and biological functions [34,35] (Table 1).

\section{MicroRNAs and TLRs}

miRNAs are the most studied small non-coding RNAs, representing approximately $4 \%$ of the genes in human genome and regulating more than one-third of the expressed genes post-transcriptionally [36]. Roughly, half of the miRNA genes are present in the intergenic regions under control of their own promoters or shared promoters in case of polycistronic microRNA clusters [37]. The remaining miRNA genes are located within protein-coding gene, where they are under the influence of host-gene promoters or miRNA-specific promoters $[37,38]$.

Increasing evidence indicates that miRNAs might be associated with several pathological conditions, such as cardiovascular and renal diseases [39-48]. Circulating miRNAs have been demonstrated to possess different profiles in patients with heart failure (HF), acute kidney injury (AKI), and chronic kidney disease when compared to controls, suggesting their possible use as innovative biomarkers for these conditions.

Specifically, microRNAs include a large family of short single-stranded RNAs (around 21 nucleotides), which have emerged as critical players in genetic regulation [49]. Nahid et al. [14] have recently shown that TLRs can be directly targeted by miRNA. Rather than shutting down the TLR signaling pathway by reducing receptor expression, microRNAs can reduce TLR signaling activity by targeting the downstream signaling molecules.

Interleukin-1(IL-1) receptor-associated kinase and tumor-necrosis factor (TNF) receptor-associated factor 6 are fundamental components of the MyD88-dependent pathway for NF- $\mathrm{kB}$ activation, and they are negatively regulated by microRNA-146a [50]. This discovery implies the role of microRNA-146a in the regulation of cytokine and TLR signaling through a negative feedback regulatory loop, supporting its contribution in the establishment of endotoxin tolerance $[51,52]$.

A connection between miRNA-155 and the innate immune response has been proposed in several studies, demonstrating its amplified expression in monocytes, macrophages, and splenocytes in mice injected with LPS $[50,53,54]$. Tili et al. [54] have demonstrated both positive and negative effects of miRNA-155 on the expression of NF- $\mathrm{kB}$ signaling proteins, as well as the FAS-associated death domain protein. LPS-stimulated macrophages produce miRNAs that can regulate the expression of signaling molecules involved in TLR pathways, such as miRNA-181c (upregulated) and miRNA-155 and -125b (downregulated) [55]. 
All these miRNAs have a central function in the regulation of TNF- $\alpha$ expression during LPS stimulation to preserve homeostasis.

\section{Extracellular Vesicles}

As remarkable discovery, miRNAs have been found in the extracellular space and in biological fluids, in a relatively stable state despite the existence of RNAse [56]. These extracellular miRNAs, excreted through different and not completely understood pathways, may be protected from degradation by numerous mechanisms.

The inclusion in Extracellular Vesicles (EVs), such as microvesicles, exosomes and apoptotic bodies, and the formation of protein-microRNA complex, have been reported as possible mechanisms against RNAse degradation [42]. EVs are released by different types of activated cells and may be internalized in target cells modulating their behavior: EV biological activities are mainly mediated by the transfer of genetic material to target cells [57]. In fact, EVs enclose a specific subset of common proteins related to biogenesis and trafficking, as well as precise and specific components derived from their origin cell or tissue $[58,59]$, such as proteins and nucleic acids [60-62]. Consequently, the specific analysis of the proteome and the nucleic acid present in EVs may offer information about the cell or tissue of origin and, especially, their physiological condition. Recently, many studies underlined the important role of EVs in inflammation, coagulation, vascular function, and their physiological and pathological effects during sepsis; they may represent important contributors to multiorgan failure in septic shock [63-66].

\section{Endotoxin Effects on Cardiac Function}

\section{Septic Cardiomyopathy Pathogenesis}

During a gram-negative infection, the immune system's reaction to the extremely conserved lipid A component of LPS may lead to serious generalized inflammation, manifesting clinically as septic shock with multiple organ dysfunction, in particular with myocardial depression and renal impairment [7-11].

Cardiac dysfunction is a clinical feature of sepsis and contributes to its mortality. In the heart, there are both infiltrating and resident immune cells expressing TLR4. Consequently, activation of TLR4 signaling pathways may directly induce myocyte dysfunction, or it may cause leukocytes activation with production of different media- tors, such as IL- 6 and TNF- $\alpha$, responsible for cardiac injury.

Indeed, functional TLR4 has been observed in various conditions, such as failing myocardium [67], myocarditis [68], and in the heart of endotoxemic mice [69]. TLR4 is the receptor for LPS which has been demonstrated to depress heart contractile function, thus reducing left ventricular pressure, rates of pressure generation and of relaxation [70-78]. Indeed, Nemoto et al. [79] have demonstrated that LPS-induced cardiac depression may be basically prevented in $\mathrm{C} 3 \mathrm{H} / \mathrm{HeJ}$ mice with non-functional TLR4. The absence of TLR4 would efficiently block LPS-induced cytokine storm and produce survival benefit.

Even though it would seem reasonable to conclude that TLR4 plays a fundamental function in the pathogenesis of cardiac dysfunction during sepsis, the cellular source (myocyte or leukocyte) of this receptor has not been still defined. For this reason, the molecular mechanisms implicated in the pathogenesis of myocyte dysfunction induced by LPS remain largely unclear. Two pathogenetic hypotheses have been proposed. According to the first one, LPS might induce a direct activation and depression of myocytes, whereas the second one suggests an involvement of immune cells (non-myocyte sources), such as macrophages resident in the heart tissue, mast cells, and infiltrating blood leukocytes (neutrophils and monocytes), reacting to LPS and diminishing myocyte function [80] (Fig. 1).

Although in vitro data suggest that LPS does not directly trigger myocytes through TLR4 in the short term (up to $3 \mathrm{~h}$ ), as reported by Tavener et al. [80], longer times of exposure to LPS might affect the cardiac function. Mitochondrial dysfunction, cell death, and autonomic dysregulation might be implicated in the pathophysiology of myocardial impairment in the setting of sepsis [81]. LPS may also activate neutrophils, mast cells, and macrophages, thus inducing cytokines and chemokines production, histamine release, platelet activation, and free radicals increase. Moreover, circulating factors, such as TNF- $\alpha$, IL-1 $\beta$, lysozyme c, endothelin- 1 seem to have direct inhibitory effects on myocyte contractility, thus participating in the pathogenesis of septic cardiomyopathy [81] (Fig. 2).

\section{Endotoxin and HF}

Endotoxin seems to be involved in the setting of $\mathrm{HF}$ as well. Indeed, there is increasing literature on sustaining the role of the gut in the pathogenesis and pathobiology of HF ("gut hypothesis of HF") [82]. The gut is a blood- 


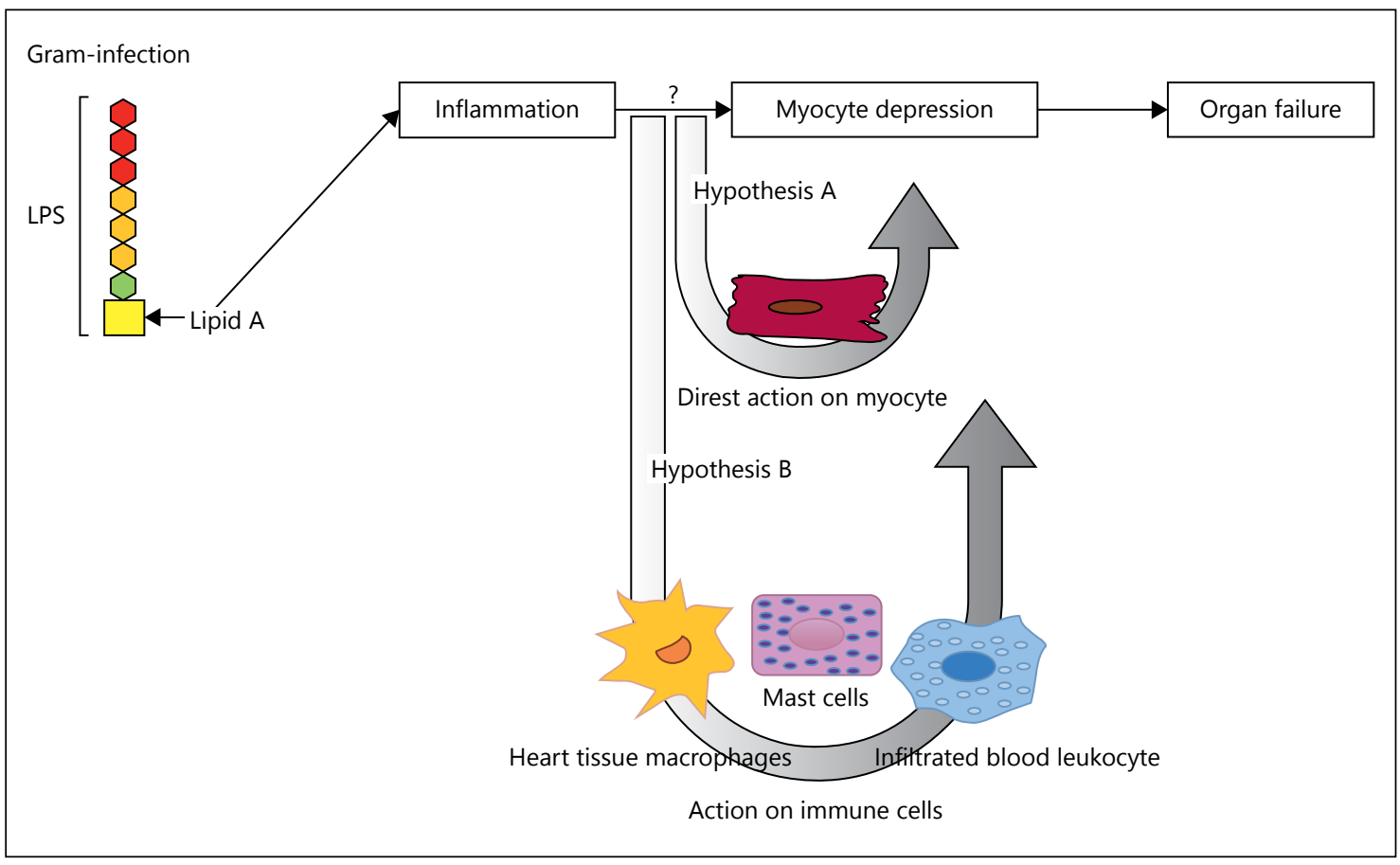

Fig. 1. Mechanisms involved in the pathogenesis of cardiac dysfunction in the setting of sepsis.

Fig. 2. Pathogenesis of septic cardiomyopa-

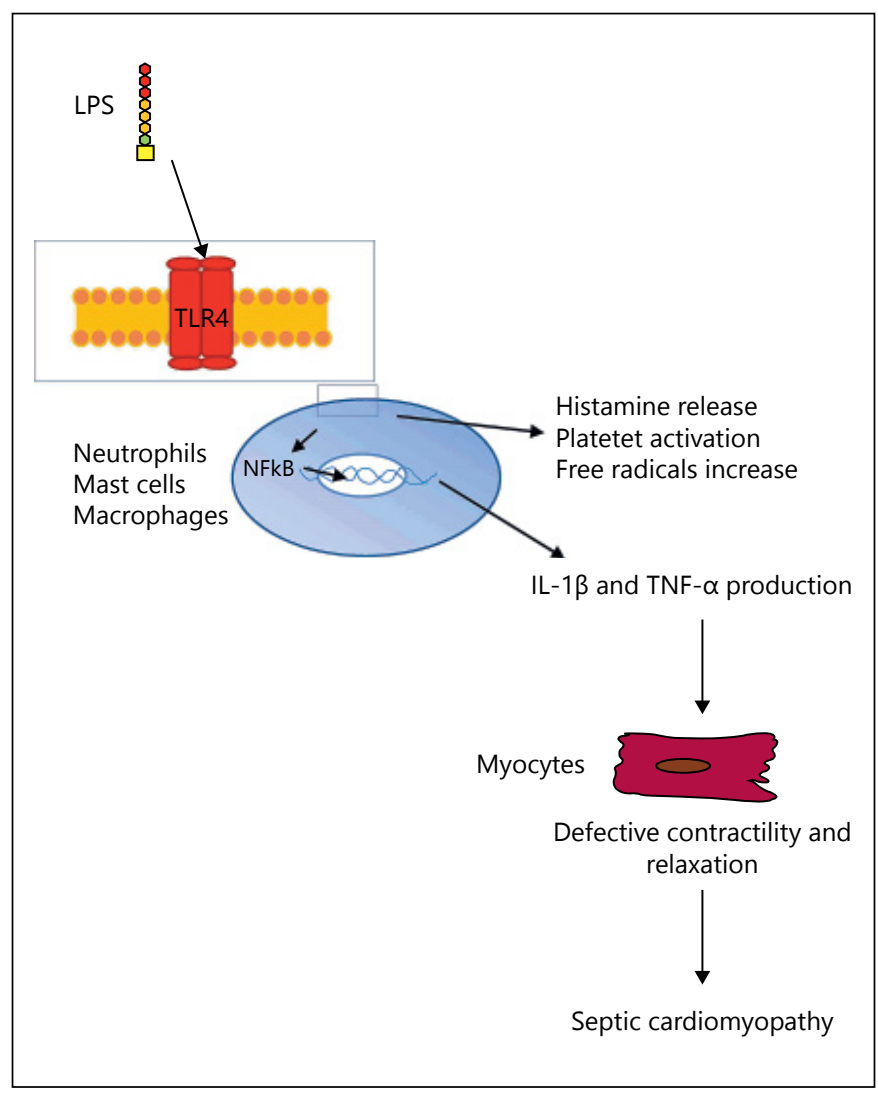
thy. 
demanding organ, in particular, villi are inclined to functional ischemia because of the decreased blood flow [83]. In patients with HF, the reduced cardiac output and the redistribution of systemic circulation lead to a decrease in intestinal perfusion and mucosal ischemia. Intestinal ischemia can be demonstrated by a reduction of intestinal mucosal $\mathrm{pH}$ or reduced passive carrier-mediated transport of $\mathrm{D}$-xylose $[84,85]$. Intestinal hypoperfusion can further disrupt the mucosa of the intestine, thus leading to improved gut permeability, bacterial translocation, and circulating endotoxins [82]. LPS may penetrate the mesenteric lymph nodes or the systemic circulation and stimulate cytokine production, such as IL- 6 and TNF- $\alpha$, through its action on mononuclear cells.

Indeed, it has been demonstrated in humans that bacteria or endotoxins may translocate into the systemic circulation in the absence of systemic or local infections. Dinakaran et al. [86] have observed elevated concentrations of bacterial DNA in patients with heart disease compared to healthy subjects, and even bacteria composition was found to differ between the groups. The intricate interaction between the heart and the gut has recently emerged as an innovative concept to provide new insights in the setting of HF.

\section{Endotoxin Effects on Renal Function}

\section{Septic AKI Pathogenesis}

AKI is a serious complication of systemic gram-negative sepsis, but the exact mechanisms involved in its pathogenesis remain only partially understood [87]. Endotoxin-induced renal dysfunction has been widely reported in humans, as well as in experimental models of endotoxemia, sepsis, and septic shock [9-11]. Indeed, systemic endotoxin administration displays a huge platform of effects induced by the release of different biologically active mediators, responsible for the impairment of renal blood flow, glomerular filtration rate, and tubular dysfunction [88].

Traditionally, septic AKI has been thought to be a consequence of a demand and perfusion mismatch, whereby renal blood flow was decreased in the midst of higher metabolic demand $[89,90]$. Nevertheless, in spite of conflicting animal studies, Langenberg et al. [91] reported only 3 studies in humans that have directly calculated renal blood flow in septic AKI via invasive measurements. All 3 studies demonstrated that septic AKI is characterized by renal arterial vasodilation and preserved overall renal blood flow [92-94].

Endotoxin: Cardiac and Renal Effects
Thus, Bellomo et al. [95] have proposed an innovative idea of septic AKI, the so-called hyperemic AKI. Indeed, glomerular filtration rate and cellular perfusion can diminish even if the overall renal blood flow is improved due to imbalanced vascular resistance between the afferent and efferent arterioles, regional microvascular flow rates, or renal venous congestion [91, 96]. Renal and central venous pressures are often augmented in septic patients as a potential effect of the so-called fluid challenge of the first hours after intensive ICU admission. This relative venous hypertension may trigger microvascular congestion and tissue edema, thus affecting glomerular filtration rate. To sustain this hypothesis, a retrospective analysis of $105 \mathrm{ICU}$ patients demonstrated a correlation between central venous pressure and AKI incidence or duration [97]. Furthermore, it has been observed that fluid overload is independently associated with death and worse renal outcomes in septic patients [98].

Also data from animal studies have challenged the concept that during sepsis, $\mathrm{AKI}$ is simply a consequence of ischemic injury due to tissue hypoperfusion. In a hyperdynamic, endotoxemic pig model, despite a significant increase in the overall kidney blood flow after treatment with LPS, almost all of the increased blood flow was shunted to the medulla, with no increase in cortical blood flow [99]. Moreover, other studies have confirmed in vitro that plasma obtained from patients with sepsis-associated AKI induced tubular epithelial cell dysfunction with consequent cell death and apoptosis without the contribution of any ischemia-reperfusion injury [100].

Based on these observations, septic AKI can be considered as the result of many concomitant aspects: a dysfunction of the renal microvascular system, the direct interaction of pathogen fragments with renal resident cells, the cytotoxic effects caused by cytokine storm, and finally the deleterious and vicious cross-talk between injured organs [101].

\section{Septic AKI and Molecular Mechanisms}

At the molecular level, the general inflammatory state of sepsis is initiated when systemic TLRs interact with their ligands. TLR4 mRNA presence has been observed in human kidney tissue, as well as in murine renal cortex, and at lower levels in the medulla. In the cortex, the expression is most conspicuous in proximal and distant tubules, and in Bowman's capsular epithelium [102].

In animal models of systemic gram-negative sepsis, TLR4 levels augmented in all tubules, both proximal and 
Fig. 3. Systemic and direct injury pathways involved in the pathogenesis of acute kidney injury.

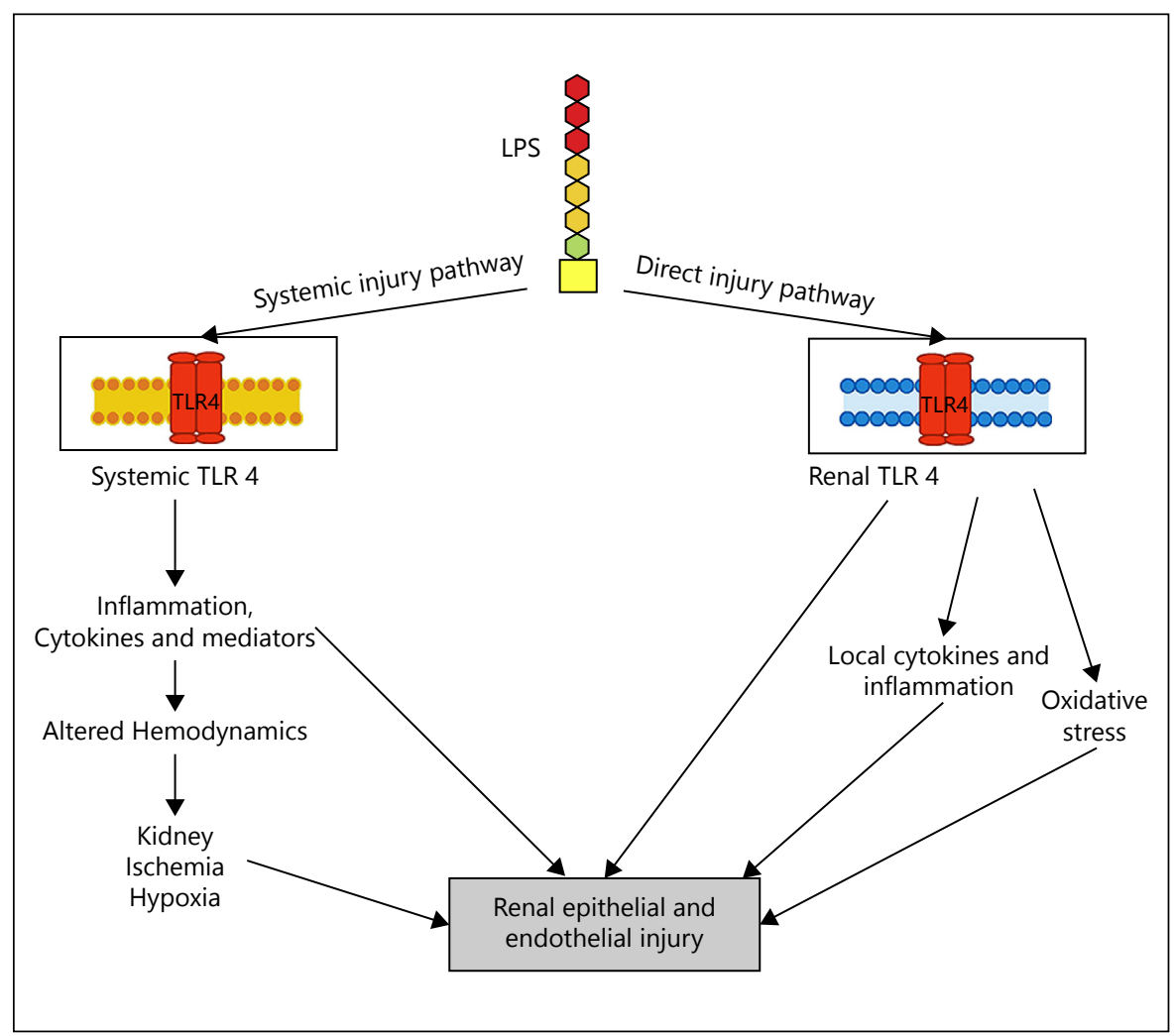

distal, with a noticeable apical distribution [103]. A strong TLR4 signal has been noticed in glomeruli and peri-tubular capillaries as well, and co-localized with CD14 expression. Systemic endotoxin is filtered and then taken up by proximal tubular cells by the apical membrane where TLR4 and CD14 are expressed [104]. Thus, the direct interaction between endotoxin and tubules may cause renal alterations in addition to the systemic effects of LPS [105] (Fig. 3).

The capacity of TLR4 to respond to pathogen-associated molecular patterns as well as to damage-associated molecular patterns offers a probable link between systemic inflammation and kidney damage, which is independent of ischemia and hypotension. Furthermore, Mariano et al. [100] have demonstrated that LPS decreases the expression of endocytic receptors, megalin and cubilin, in the apical portion of proximal tubular epithelial cells, causing an interference with the normal processes of protein re-absorption, thus contributing to the characteristic low molecular weight proteinuria present in septic patients.

A spectrum of renal lesions in the setting of gram-negative sepsis has been reported, ranging from marginal histological alterations, such as tubular swelling and vacuol- ization, to grave inflammation, oxidative stress, and extensive apoptosis [104, 106, 107]. Indeed, caspase inhibition has been found to prevent apoptotic proximal, distal, and peri-tubular cell death in LPS animal models of septic AKI [11]. In this context, Cantaluppi et al. [10] have demonstrated the role of Fas, caspases, and apoptosis in septic AKI as well.

Mitochondrial dysfunction, resulting in reduced ATP production and bioenergetic failure, is also known as an important pathogenic factor in sepsis-associated AKI [108]. Mitochondrial injury clearly arises in human sepsis, as evidenced by biochemical and structural changes, such as decreased mitochondrial mass, disruption of cristae, and extensive mitochondrial swelling in tissue biopsies obtained in ICU $[109,110]$.

\section{Septic AKI and Organ Crosstalk}

A supplementary mechanism of renal injury during sepsis is probably connected to detrimental crosstalk. Apart from the consolidated models of hepatorenal and CRS, current studies have revealed the effects of lung, brain, and bone marrow on kidney function.

Indeed, it has been shown that pneumocytes of patients treated by mechanical invasive ventilation pro- 
duce IL- $1 \beta$, IL- 6 , IL- 8 , and TNF- $\alpha$ after ventilator-induced barotraumas, thus promoting tubular cell apoptosis and AKI [101]. Furthermore, the enormous cytokine release found after traumatic brain injury is considered a putative additional reason of tubular cell dysfunction, and it has been related to delayed graft function after donation for kidney transplantation [111]. Finally, recent findings propose that AKI may contribute to the development of the systemic inflammatory state. Naito et al. [112] demonstrated in vivo increased RNA-polymerase II density at TNF- $\alpha$, monocyte chemotactic protein-1, and heme oxygenase- 1 loci in mice model treated by LPS, due to selective histone methylation. These AKIassociated epigenetic modifications of tubular cells may contribute to the systemic enhancement in inflammatory mediators, which are involved in multiorgan dysfunction.

\section{Endotoxin and CRS}

Sepsis-Induced CRS Type 5 and Experimental Data

Sepsis-induced CRS type 5 is characterized by a rapid disease process with dramatic effects on both kidney and heart functions. Changes in systems physiology in the setting of sepsis can result from the systemic effects of sepsis itself, from the septic injury to "systemic pathways", or from the heart-kidney crosstalk between these damaged organs $[113,114]$.

During combined acute cardiac and renal dysfunctions, such as in sepsis, there are marked cellular, subcellular, and molecular changes in each organ. Despite the limitations of existing data about the effects of endotoxin on cardiorenal interactions, TLR activation, apoptosis induction, and cytokine release are well documented in heart and kidney in case of gram-negative sepsis [76].

Brocca et al. [12], in an innovative case-control study, have recently reported that plasma from CRS type $5 \mathrm{pa}-$ tients is able to trigger cellular apoptosis through the activation of caspase- 3 , caspase- 8 , and caspase- 9 , and induces the loss of cellular viability in renal tubular epithelial cells. The authors have also demonstrated significant higher levels of inflammatory cytokines, such as IL-6, IL-10, IL-8, IL- $1 \beta$, and IFN- $\gamma$ in patients with CRS type 5 compared to healthy subjects. Furthermore, Virzì et al. [115] observed a significant in vitro increase in cellular apoptosis in renal tubular cells incubated with plasma from CRS type 5 patients positive for endotoxin.

Endotoxin: Cardiac and Renal Effects
Septic hearts are characterized by depressed contractile function due to abnormal muscle protein expression, reduced dystrophin and associated glycoproteins amount, and altered L-type calcium currents [76, 116]. Diminished cardiac output induces reduced renal perfusion, which further aggravates sepsis-induced AKI. Beyond the hemodynamic effects of the impaired heart on renal circulation, cardiac changes due to altered renal fluid balance are present.

In the kidney, LPS impairs glomerular filtration rate, as well as tubular function with consequent fluid and electrolyte alterations $[117,118]$. Moreover, endotoxin has been demonstrated to induce a time- and dose-dependent suppression of megalin and cubilin expressions, responsible for increased urinary albumin loss in mice [119]. Consequently, fluid overload due to AKI leads to chronic HF in the setting of dilated hearts, and metabolic acidosis can affect cardiac contractility and amplify heart rate, thus worsening the myocardial workload.

\section{Contributing Factors for CRS Type 5 Development}

The management of sepsis can contribute to the development of CRS type 5. Indeed, fluid resuscitation together with enhanced vascular permeability leads to edema in organs and tissues, thus resulting in an abdominal compartment syndrome with a higher renal venous pressure and lower renal perfusion [120]. Furthermore, the use of contrast agents for imaging studies may cause both myocardial depression and tubular toxicity.

The harmful role of venous congestion and volume overload, and their link with endotoxemia has been recognized in chronic CRS as well. Anker et al. [121] suggested that volume overload and subsequent mesenteric venous congestion induces bowel wall edema with translocation of gram-negative bacteria through the intestinal villi and LPS release into the circulation. These results coupled with the observation of a subsequent reduction in systemic endotoxin levels after the resolution of the acute decompensation episode, support the possibility of a mechanistic connection between venous congestion and endotoxin translocation in chronic HF [122].

Similarly, endotoxin levels have been recently established to be elevated in chronic kidney disease patients with signs of fluid overload compared to patients without volume overload [123]. Circulating LPS stimulates the release of TNF- $\alpha$ and IL-6, which further activate NF- $\mathrm{kB}$, thus inducing cardiorenal depression and worsening bowel edema [124]. Therefore, venous congestion and 


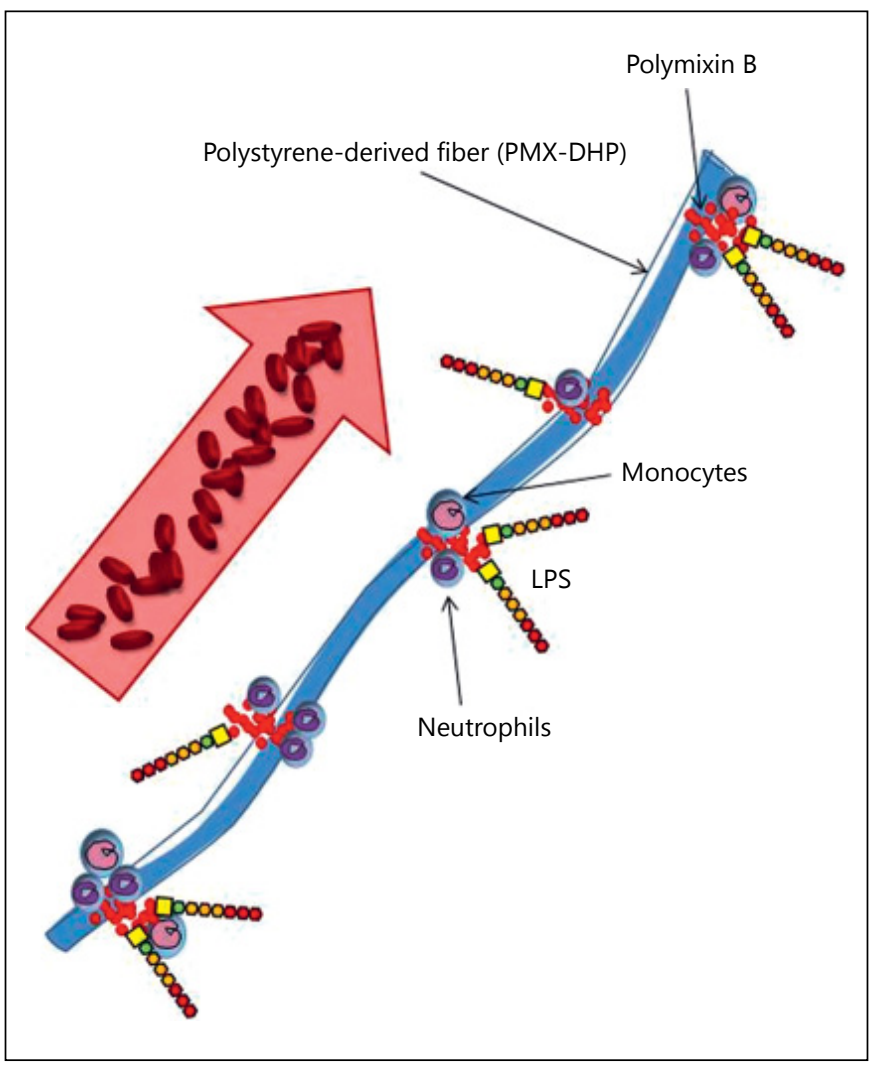

Fig. 4. Polymyxin B cartridge.

volume overload can induce a dangerous inflammatory state with consequent elevations of inflammatory mediators, such as endotoxin, in the setting of both acute and chronic CRS.

\section{Targeted Therapies in Gram-Negative Sepsis}

Gram-negative sepsis is characterized by a combination of direct and indirect effects of endotoxin, which is responsible for the release of an enormous array of inflammatory mediators. Based on this observation, it is rational to antagonize and/or to remove endotoxin when treating patients with sepsis $[15,16]$. Pharmacological approaches based on targeting specific pathways contributing to the pathogenesis of organ dysfunction in sepsis have failed. Indeed, clinical trials aimed at antagonizing a single mediator, such as LPS, TNF- $\alpha$, IL- $1 \beta$, and TLR4 did not result in any significant improvements [125]. This may be, in part, clarified by the early deregulated host immune response, characterized by a condition of immunosuppression.
In the last few decades, many studies have estimated the clinical and biological effects of various extracorporeal blood purification techniques in sepsis, both in terms of renal support and immunomodulation. Large clinical trials have suggested that in septic AKI, early initiation of continuous renal replacement therapy is associated with a better hemodynamic profile and outcome.

\section{Polymyxin B Cartridge}

A novel therapeutic approach whereby polymyxin $B$ is immobilized to a polystyrene-derived fiber (PMX-DHP) in a hemoperfusion device has been recently proposed to remove circulating endotoxin [126]. The PMX cartridge is able to absorb LPS, filtering blood externally with the use of an extracorporeal circuit. This relies on both the polystyrene-PMX B bonding and the LPS-PMX B affinity. The first one is the covalent linkage of PMX B to the fiber surface, thus avoiding the nephrotoxic and neurotoxic effects of PMX B. The second bond is represented by the stable interaction between Lipid A and PMX B hydrophobic residues (Fig. 4). Moreover, polymyxin B has pleiotropic effects, counting for the entrapment of inflammatory cells, such as monocytes and neutrophils, and the clearance of cytokines (such as TNF- $\alpha$ and IL-6), with the resulting reduction in the intracellular mechanisms of apoptosis.

\section{Studies on Polymyxin B Cartridge}

There are many published trials of small cohorts of patients as well as case reports and case series reporting the efficacy of PMX-DHP in severe sepsis. In a systematic review and meta-analysis of 28 trials on septic patients performed by Cruz et al. [127], polymyxin B hemoperfusion was found to be associated with improved hemodynamics and oxygenation, as well as a decreased mortality. However, the sample size of this meta-analysis was small.

In 2009, a randomized unblinded study of 64 patients in 10 Italian ICUs (Early Use of Polymyxin Hemoperfusion in Abdominal Septic Shock) reported an improved hemodynamics and renal function [128]. The Early Use of Polymyxin Hemoperfusion in Abdominal Septic Shock 2 is a web-based registry of patients treated with PMXDHP, performed to validate the reproducibility of the treatment in the daily practice [129]. It is the largest registry conducted outside Japan on the clinical use of PMXDHP in the setting of sepsis. Data analysis confirmed the feasibility of the treatment in daily clinical practice, showing clinical benefits derived from the endotoxin removal 
without significant adverse effect related to the extracorporeal technique.

The first randomized and controlled trial (Evaluating the Use of Polymyxin B Hemoperfusion in a Randomized controlled trial of Adults Treated for Endotoxemia and Septic Shock - EUPHRATES) is still ongoing in US and Canada [130].

\section{Conclusion}

Experimental and clinical studies have suggested the presence of a detrimental vicious crosstalk between cardiac and renal systems in the setting of sepsis, and cardiorenal type 5 occurs when an overwhelming insult leads to concurrent acute cardiac dysfunction and AKI.

Recent data suggest that heart and kidney dysfunctions are associated with the damaging activity of circulating pro-inflammatory and pro-apoptotic mediators, which trigger cellular apoptosis, autophagy, cell cycle ar- rest, and miRNA activation. Early identification of sepsisassociated AKI and heart dysfunction may improve patient clinical outcome.

Moreover, novel therapeutic strategies based on pharmacological agents and extracorporeal blood purification techniques have been developed, and they might represent new areas for further studies.

\section{Ethics Statement}

No ethics committee approval was required.

\section{Funding Source}

No grant, funding or support was necessary.

\section{Disclosure Statement}

No conflict of interest, financial or otherwise for all authors.

\section{References}

1 Stasi A, Intini A, Divella C, Franzin R, Montemurno E, Grandaliano G, et al: Emerging role of Lipopolysaccharide binding protein in sepsis-induced acute kidney injury. Nephrol Dial Transplant 2017;32:24-31.

2 Ostuni R, Zanoni I, Granucci F: Deciphering the complexity of toll-like receptor signaling. Cell Mol Life Sci 2010;67:4109-4134.

3 Riedemann NC, Guo RF, Ward PA: The enigma of sepsis. J Clin Invest 2003;112:460-467.

4 Ianaro A, Tersigni M, D'Acquisto F: New insight in LPS antagonist. Mini Rev Med Chem 2009:9:306-317.

5 Romaschin AD, Klein DJ, Marshall JC: Bench-to-bedside review: clinical experience with the endotoxin activity assay. Crit Care 2012:16:248.

6 Oblak A, Jerala R: The molecular mechanism of species-specific recognition of lipopolysaccharides by the MD-2/TLR4 receptor complex. Mol Immunol 2015;63:134-142.

7 Reilly JM, Cunnion RE, Burch-Whitman C, Parker MM, Shelhamer JH, Parrillo JE: A circulating myocardial depressant substance is associated with cardiac dysfunction and peripheral hypoperfusion (lactic acidemia) in patients with septic shock. Chest 1989;95: 1072-1080.

8 Lefer AM: Mechanisms of cardiodepression in endotoxin shock. Circ Shock Suppl 1979;1: $1-8$.

9 Jo SK, Cha DR, Cho WY, Kim HK, Chang $\mathrm{KH}$, Yun SY, et al: Inflammatory cytokines and lipopolysaccharide induce Fas-mediated apoptosis in renal tubular cells. Nephron 2002;91:406-415.

10 Cantaluppi V, Weber V, Lauritano C, Figliolini F, Beltramo S, Biancone L, et al: Protective effect of resin adsorption on septic plasma-induced tubular injury. Crit Care 2010; 14:R4.

11 Guo R, Wang Y, Minto AW, Quigg RJ, Cunningham PN: Acute renal failure in endotoxemia is dependent on caspase activation. J Am Soc Nephrol 2004;15:3093-3102.

12 Brocca A, Virzì GM, Pasqualin C, Pastori S, Marcante S, de Cal M, et al: Cardiorenal syndrome type 5: in vitro cytotoxicity effects on renal tubular cells and inflammatory profile. Anal Cell Pathol (Amst) 2015;2015: 469461.

13 McCullough PA, Kellum JA, Haase M, Müller C, Damman K, Murray PT, et al: Pathophysiology of the cardiorenal syndromes: executive summary from the eleventh consensus conference of the Acute Dialysis Quality Initiative (ADQI). Contrib Nephrol 2013;182:82-98.

14 Nahid MA, Satoh M, Chan EK: MicroRNA in TLR signaling and endotoxin tolerance. Cell Mol Immunol 2011;8:388-403.

15 Danner RL, Elin RJ, Hosseini JM, Wesley RA, Reilly JM, Parillo JE: Endotoxemia in human septic shock. 1991. Chest 2009;136(5 suppl): e30.

16 Brandtzaeg P, Mollnes TE, Kierulf P: Complement activation and endotoxin levels in sys- temic meningococcal disease. J Infect Dis 1989:160:58-65.

17 Ronco C, Piccinni P, Kellum J: Rationale of extracorporeal removal of endotoxin in sepsis: theory, timing and technique. Contrib Nephrol 2010;167:25-34.

18 Calabrese V, Cighetti R, Peri F: Molecular simplification of lipid A structure: TLR4modulating cationic and anionic amphiphiles. Mol Immunol 2015;63:153-161.

19 Lakhani SA, Bogue CW: Toll-like receptor signaling in sepsis. Curr Opin Pediatr 2003; 15:278-282.

20 Anderberg SB, Luther T, Frithiof R: Physiological aspects of toll-like receptor 4 activation in sepsis-induced acute kidney injury. Acta Physiol (Oxf) 2017:219:573-588.

21 Hoshino K, Takeuchi O, Kawai T, Sanjo H, Ogawa T, Takeda Y, et al: Cutting edge: tolllike receptor 4 (TLR4)-deficient mice are hyporesponsive to lipopolysaccharide: evidence for TLR4 as the Lps gene product. J Immunol 1999; 162:3749-3752.

22 Qureshi ST, Lariviere L, Leveque G, Clermont S, Moore KJ, Gros P, et al: Endotoxintolerant mice have mutations in toll-like receptor 4 (Tlr4).J Exp Med 1999;189:615625 .

23 Shimazu R, Akashi S, Ogata H, Nagai Y, Fukudome K, Miyake K, et al: MD-2, a molecule that confers lipopolysaccharide responsiveness on toll-like receptor 4. J Exp Med 1999; 189:1777-1782. 
24 Schromm AB, Lien E, Henneke P, Chow JC, Yoshimura A, Heine $\mathrm{H}$, et al: Molecular genetic analysis of an endotoxin nonresponder mutant cell line: a point mutation in a conserved region of MD-2 abolishes endotoxininduced signaling. J Exp Med 2001;194:7988.

25 Nagai Y, Akashi S, Nagafuku M, Ogata M, Iwakura Y, Akira S, et al: Essential role of MD-2 in LPS responsiveness and TLR4 distribution. Nat Immunol 2002;3:667-672.

26 Peri F, Piazza M, Calabrese V, Damore G, Cighetti R: Exploring the LPS/TLR4 signal pathway with small molecules. Biochem Soc Trans 2010;38:1390-1395.

27 Tavener SA, Kubes P: Is there a role for cardiomyocyte toll-like receptor 4 in endotoxemia? Trends Cardiovasc Med 2005; 15:153157.

28 Medzhitov R, Preston-Hurlburt P, Janeway CA Jr: A human homologue of the Drosophila Toll protein signals activation of adaptive immunity. Nature 1997;388:394-397.

29 Sun BK, Tsao H: Small RNAs in development and disease. J Am Acad Dermatol 2008;59: 725-737; quiz 38-40.

30 Pritchard CC, Cheng HH, Tewari M: MicroRNA profiling: approaches and considerations. Nat Rev Genet 2012;13:358-369.

31 Khare S, Zhang Q, Ibdah JA: Epigenetics of hepatocellular carcinoma: role of microRNA. World J Gastroenterol 2013;19:5439-5445.

32 Aalto AP, Pasquinelli AE: Small non-coding RNAs mount a silent revolution in gene expression. Curr Opin Cell Biol 2012;24:333-340.

33 Pasquinelli AE: MicroRNAs and their targets: recognition, regulation and an emerging reciprocal relationship. Nat Rev Genet 2012;13: 271-282.

34 Farazi TA, Juranek SA, Tuschl T: The growing catalog of small RNAs and their association with distinct Argonaute/Piwi family members. Development 2008;135:1201-1214.

35 Kaikkonen MU, Lam MT, Glass CK: Noncoding RNAs as regulators of gene expression and epigenetics. Cardiovasc Res. 2011;90: 430-440.

36 Bentwich I, Avniel A, Karov Y, Aharonov R, Gilad S, Barad O, et al: Identification of hundreds of conserved and nonconserved human microRNAs. Nat Genet 2005;37:766-770.

37 Rodriguez A, Griffiths-Jones S, Ashurst JL, Bradley A: Identification of mammalian microRNA host genes and transcription units. Genome Res 2004;14:1902-1910.

38 Bartel DP: MicroRNAs: target recognition and regulatory functions. Cell 2009;136:215233.

39 Vettori S, Gay S, Distler O: Role of microRNAs in fibrosis. Open Rheumatol J 2012;6: 130-139.

40 Zhang C: Novel functions for small RNA molecules. Curr Opin Mol Ther 2009;11:641-651.

41 Friedman JM, Jones PA: MicroRNAs: critical mediators of differentiation, development and disease. Swiss Med Wkly 2009;139:466472 .
42 Lorenzen JM, Batkai S, Thum T: Regulation of cardiac and renal ischemia-reperfusion injury by microRNAs. Free Radic Biol Med 2013;64:78-84.

43 Lorenzen JM, Thum T: Circulating and urinary microRNAs in kidney disease. Clin J Am Soc Nephrol 2012;7:1528-1533.

44 Lorenzen JM, Kielstein JT, Hafer C, Gupta SK, Kumpers P, Faulhaber-Walter R, et al: Circulating miR-210 predicts survival in critically ill patients with acute kidney injury. Clin J Am Soc Nephrol 2011;6:15401546.

45 van Rooij E, Sutherland LB, Liu N, Williams $\mathrm{AH}$, McAnally J, Gerard RD, et al: A signature pattern of stress-responsive microRNAs that can evoke cardiac hypertrophy and heart failure. Proc Natl Acad Sci U S A 2006;103: 18255-18260.

46 Tijsen AJ, Creemers EE, Moerland PD, de Windt LJ, van der Wal AC, Kok WE, et al: MiR423-5p as a circulating biomarker for heart failure. Circ Res 2010;106:1035-1039.

47 Wijnen WJ, van der Made I, van den Oever S, Hiller M, de Boer BA, Picavet DI, et al: Cardiomyocyte-specific miRNA-30c over-expression causes dilated cardiomyopathy. PLoS One 2014;9:e96290.

48 Kato M, Arce L, Natarajan R: MicroRNAs and their role in progressive kidney diseases. Clin J Am Soc Nephrol 2009;4:1255-1266.

49 Filipowicz W, Bhattacharyya SN, Sonenberg $\mathrm{N}$ : Mechanisms of post-transcriptional regulation by microRNAs: are the answers in sight? Nat Rev Genet 2008;9:102-114.

50 Taganov KD, Boldin MP, Chang KJ, Baltimore D: NF-kappaB-dependent induction of microRNA miR-146, an inhibitor targeted to signaling proteins of innate immune responses. Proc Natl Acad Sci U S A 2006;103:1248112486.

51 Nahid MA, Satoh M, Chan EK: Mechanistic role of microRNA-146a in endotoxin-induced differential cross-regulation of TLR signaling. J Immunol 2011;186:1723-1734.

52 Nahid MA, Pauley KM, Satoh M, Chan EK MiR-146a is critical for endotoxin-induced tolerance: IMPLICATION IN INNATE IMMUNITY. J Biol Chem 2009;284:3459034599.

53 O'Connell RM, Taganov KD, Boldin MP, Cheng G, Baltimore D: MicroRNA-155 is induced during the macrophage inflammatory response. Proc Natl Acad Sci U S A 2007;104: 1604-1609.

54 Tili E, Michaille JJ, Cimino A, Costinean S, Dumitru CD, Adair B, et al: Modulation of miR-155 and miR-125b levels following lipopolysaccharide/TNF-alpha stimulation and their possible roles in regulating the response to endotoxin shock. J Immunol 2007;179: 5082-5089.

55 Androulidaki A, Iliopoulos D, Arranz A, Doxaki C, Schworer S, Zacharioudaki V, et al: The kinase Aktl controls macrophage response to lipopolysaccharide by regulating microRNAs. Immunity 2009;31:220-231.
56 Gupta SK, Bang C, Thum T: Circulating microRNAs as biomarkers and potential paracrine mediators of cardiovascular disease. Circ Cardiovasc Genet 2010;3:484-488.

57 Camussi G, Deregibus MC, Bruno S, Cantaluppi V, Biancone L: Exosomes/microvesicles as a mechanism of cell-to-cell communication. Kidney Int 2010;78:838-848.

58 Mathivanan S, Lim JW, Tauro BJ, Ji H, Moritz RL, Simpson RJ: Proteomics analysis of A33 immunoaffinity-purified exosomes released from the human colon tumor cell line LIM1215 reveals a tissue-specific protein signature. Mol Cell Proteomics 2010;9:197-208.

59 Raposo G, Stoorvogel W: Extracellular vesicles: exosomes, microvesicles, and friends. J Cell Biol 2013;200:373-383.

60 Wang Z, Hill S, Luther JM, Hachey DL, Schey KL: Proteomic analysis of urine exosomes by multidimensional protein identification technology (MudPIT). Proteomics 2012;12:329338.

61 Lazaro-Ibanez E, Sanz-Garcia A, Visakorpi T, Escobedo-Lucea C, Siljander P, Ayuso-Sacido A, et al: Different gDNA content in the subpopulations of prostate cancer extracellular vesicles: apoptotic bodies, microvesicles, and exosomes. Prostate 2014;74:1379-1390.

62 Wang D, Sun W: Urinary extracellular microvesicles: isolation methods and prospects for urinary proteome. Proteomics 2014;14: 1922-1932.

63 Reid VL, Webster NR: Role of microparticles in sepsis. Br J Anaesth 2012;109:503-513.

64 Delabranche X, Boisrame-Helms J, Asfar P, Berger A, Mootien Y, Lavigne T, et al: Microparticles are new biomarkers of septic shock-induced disseminated intravascular coagulopathy. Intensive Care Med 2013;39: 1695-1703.

65 Hellum M, Ovstebo R, Brusletto BS, Berg JP, Brandtzaeg P, Henriksson CE: Microparticleassociated tissue factor activity correlates with plasma levels of bacterial lipopolysaccharides in meningococcal septic shock. Thromb Res 2014;133:507-514.

66 Souza AC, Yuen PS, Star RA: Microparticles: markers and mediators of sepsis-induced microvascular dysfunction, immunosuppression, and AKI. Kidney Int 2015;87:11001108.

67 Frantz S, Kobzik L, Kim YD, Fukazawa R, Medzhitov R, Lee RT, et al: Toll4 (TLR4) expression in cardiac myocytes in normal and failing myocardium. J Clin Invest 1999;104: 271-280.

68 Satoh M, Nakamura M, Akatsu T, Iwasaka J, Shimoda Y, Segawa I, et al: Expression of tolllike receptor 4 is associated with enteroviral replication in human myocarditis. Clin Sci (Lond) 2003;104:577-584.

69 Baumgarten G, Knuefermann P, Nozaki N, Sivasubramanian N, Mann DL, Vallejo JG: In vivo expression of proinflammatory mediators in the adult heart after endotoxin administration: the role of toll-like receptor-4. J Infect Dis 2001;183:1617-1624. 
70 Thomas JA, Haudek SB, Koroglu T, Tsen MF, Bryant DD, White DJ, et al: IRAK1 deletion disrupts cardiac toll/IL-1 signaling and protects against contractile dysfunction. Am J Physiol Heart Circ Physiol 2003;285:H597H606.

71 Thompson M, Kliewer A, Maass D, Becker L, White DJ, Bryant D, et al: Increased cardiomyocyte intracellular calcium during endotoxin-induced cardiac dysfunction in guinea pigs. Pediatr Res 2000;47:669-676.

72 Natanson C, Danner RL, Elin RJ, Hosseini JM, Peart KW, Banks SM, et al: Role of endotoxemia in cardiovascular dysfunction and mortality. Escherichia coli and Staphylococcus aureus challenges in a canine model of human septic shock. J Clin Invest 1989;83:243251.

73 Ognibene FP, Parker MM, Natanson C, Shelhamer JH, Parrillo JE: Depressed left ventricular performance. Response to volume infusion in patients with sepsis and septic shock. Chest 1988;93:903-910.

74 Parker MM, Shelhamer JH, Bacharach SL, Green MV, Natanson C, Frederick TM, et al: Profound but reversible myocardial depression in patients with septic shock. Ann of Intern Med 1984;100:483-490.

75 Suffredini AF, Fromm RE, Parker MM, Brenner M, Kovacs JA, Wesley RA, et al: The cardiovascular response of normal humans to the administration of endotoxin. N Engl J Med 1989;321:280-287.

76 Celes MR, Prado CM, Rossi MA: Sepsis: going to the heart of the matter. Pathobiology 2013; 80:70-86.

77 Celes MR, Torres-Duenas D, Prado CM, Campos EC, Moreira JE, Cunha FQ, et al: Increased sarcolemmal permeability as an early event in experimental septic cardiomyopathy: a potential role for oxidative damage to lipids and proteins. Shock 2010;33:322-331.

78 Rozenberg S, Besse S, Brisson H, Jozefowicz E, Kandoussi A, Mebazaa A, et al: Endotoxininduced myocardial dysfunction in senescent rats. Crit Care 2006;10:R124.

79 Nemoto S, DeFreitas G, Mann DL, Carabello BA: Effects of changes in left ventricular contractility on indexes of contractility in mice. Am J Physiol Heart Circ Physiol 2002; 283:H2504-H2510.

80 Tavener SA, Long EM, Robbins SM, McRae $\mathrm{KM}$, Van Remmen H, Kubes P: Immune cell toll-like receptor 4 is required for cardiac myocyte impairment during endotoxemia. Circ Res 2004;95:700-707.

81 Vieillard-Baron A, Cecconi M: Understanding cardiac failure in sepsis. Intensive Care Med 2014;40:1560-1563.

82 Nagatomo Y, Tang WH: Intersections between microbiome and heart failure: revisiting the gut hypothesis. J Card Fail 2015;21: 973-980.

83 Takala J: Determinants of splanchnic blood flow. Br J Anaesth 1996;77:50-58.

84 Krack A, Richartz BM, Gastmann A, Greim K, Lotze U, Anker SD, et al: Studies on intragas- tric $\mathrm{PCO} 2$ at rest and during exercise as a marker of intestinal perfusion in patients with chronic heart failure. Eur J Heart Fail 2004;6: 403-407.

85 Sandek A, Bjarnason I, Volk HD, Crane R, Meddings JB, Niebauer J, et al: Studies on bacterial endotoxin and intestinal absorption function in patients with chronic heart failure. Int J Cardiol 2012;157:80-85.

86 Dinakaran V, Rathinavel A, Pushpanathan M, Sivakumar R, Gunasekaran P, Rajendhran $\mathrm{J}$ : Elevated levels of circulating DNA in cardiovascular disease patients: metagenomic profiling of microbiome in the circulation. PLoS One 2014; 9:e105221.

87 Wan L, Bellomo R, Di Giantomasso D, Ronco C: The pathogenesis of septic acute renal failure. Curr Opin Crit Care 2003;9:496-502.

88 Khan RZ, Badr KF: Endotoxin and renal function: perspectives to the understanding of septic acute renal failure and toxic shock. Nephrol Dial Transplant 1999;14:814-818.

89 Schrier RW, Wang W, Poole B, Mitra A: Acute renal failure: definitions, diagnosis, pathogenesis, and therapy. J Clin Invest 2004; 114:5-14.

90 Bougle A, Duranteau J: Pathophysiology of sepsis-induced acute kidney injury: the role of global renal blood flow and renal vascular resistance. Contrib Nephrol 2011;174:89-97.

91 Langenberg C, Bellomo R, May C, Wan L, Egi M, Morgera S: Renal blood flow in sepsis. Crit Care 2005;9:R363-R374.

92 Brenner M, Schaer GL, Mallory DL, Suffredini AF, Parrillo JE: Detection of renal blood flow abnormalities in septic and critically ill patients using a newly designed indwelling thermodilution renal vein catheter. Chest 1990;98:170-179.

93 Lucas CE, Rector FE, Werner M, Rosenberg IK: Altered renal homeostasis with acute sepsis. Clinical significance. Arch Surg 1973;106: 444-449.

94 Rector F, Goyal S, Rosenberg IK, Lucas CE: Sepsis: a mechanism for vasodilatation in the kidney. Ann Surg 1973;178:222-226.

95 Wan L, Bagshaw SM, Langenberg C, Saotome T, May C, Bellomo R: Pathophysiology of septic acute kidney injury: what do we really know? Crit Care Med 2008;36(4 suppl):S198S203.

96 Molitoris BA: Renal blood flow in sepsis: a complex issue. Crit Care 2005;9:327-328.

97 Legrand M, Dupuis C, Simon C, Gayat E, Mateo J, Lukaszewicz AC, et al: Association between systemic hemodynamics and septic acute kidney injury in critically ill patients: a retrospective observational study. Crit Care 2013;17:R278.

98 Borthwick EM, Hill CJ, Rabindranath KS, Maxwell AP, McAuley DF, Blackwood B: High-volume haemofiltration for sepsis. Cochrane Database Syst Rev 2013;1:CD008075.

99 Cohen RI, Hassell AM, Marzouk K, Marini C, Liu SF, Scharf SM: Renal effects of nitric oxide in endotoxemia. Am J Respir Crit Care Med 2001;164:1890-1895.
100 Mariano F, Cantaluppi V, Stella M, Romanazzi GM, Assenzio B, Cairo M, et al: Circulating plasma factors induce tubular and glomerular alterations in septic burns patients. Crit Care 2008;12:R42.

101 Dellepiane S, Marengo M, Cantaluppi V: Detrimental cross-talk between sepsis and acute kidney injury: new pathogenic mechanisms, early biomarkers and targeted therapies. Crit Care 2016;20:61.

102 Wolfs TG, Buurman WA, van Schadewijk A de Vries B, Daemen MA, Hiemstra PS, et al: In vivo expression of toll-like receptor 2 and 4 by renal epithelial cells: IFN-gamma and TNF-alpha mediated up-regulation during inflammation. J Immunol 2002;168:12861293.

103 El-Achkar TM, Huang X, Plotkin Z, Sandoval RM, Rhodes GJ, Dagher PC: Sepsis induces changes in the expression and distribution of toll-like receptor 4 in the rat kidney. Am J Physiol Renal Physiol 2006 290:F1034-F1043.

104 El-Achkar TM, Wu XR, Rauchman M, McCracken R, Kiefer S, Dagher PC: TammHorsfall protein protects the kidney from ischemic injury by decreasing inflammation and altering TLR4 expression. Am J Physiol Renal Physiol 2008;295:F534F544.

105 El-Achkar TM, Hosein M, Dagher PC: Pathways of renal injury in systemic gram-negative sepsis. Eur J Clin Invest 2008;38(suppl 2):39-44.

106 Cunningham PN, Wang Y, Guo R, He G, Quigg RJ: Role of toll-like receptor 4 in endotoxin-induced acute renal failure. J Immunol 2004;172:2629-2635.

$107 \mathrm{Wu}$ L, Tiwari MM, Messer KJ, Holthoff JH Gokden N, Brock RW, et al: Peritubular capillary dysfunction and renal tubular epithelial cell stress following lipopolysaccharide administration in mice. Am J Physiol Renal Physiol 2007;292:F261-F268.

108 Parikh SM, Yang Y, He L, Tang C, Zhan M, Dong Z: Mitochondrial function and disturbances in the septic kidney. Semin Nephrol 2015;35:108-119.

109 Brealey D, Brand M, Hargreaves I, Heales S, Land J, Smolenski R, et al: Association between mitochondrial dysfunction and severity and outcome of septic shock. Lancet 2002;360:219-223.

110 Takasu O, Gaut JP, Watanabe E, To K Fagley RE, Sato B, et al: Mechanisms of cardiac and renal dysfunction in patients dying of sepsis. Am J Respir Crit Care Med 2013; 187:509-517.

111 Cantaluppi V, Quercia AD, Dellepiane S, Ferrario S, Camussi G, Biancone L: Interaction between systemic inflammation and renal tubular epithelial cells. Nephrol Dial Transplant 2014;29:2004-2011.

112 Naito M, Bomsztyk K, Zager RA: Endotoxin mediates recruitment of RNA polymerase II to target genes in acute renal failure. J Am Soc Nephrol 2008;19:1321-1330. 
113 Virzi G, Day S, de Cal M, Vescovo G, Ronco C: Heart-kidney crosstalk and role of humoral signaling in critical illness. Crit Care 2014;18:201.

114 Virzi GM, Clementi A, Ronco C: Cellular apoptosis in the cardiorenal axis. Heart Fail Rev 2016;21:177-189.

115 Virzi GM, Clementi A, Brocca A, de Cal M, Marcante S, Ronco C: Cardiorenal syndrome type 5 in sepsis: role of endotoxin in cell death pathways and inflammation. Kidney Blood Press Res 2016;41:10081015.

116 Stengl M, Bartak F, Sykora R, Chvojka J, Benes J, Krouzecky A, et al: Reduced L-type calcium current in ventricular myocytes from pigs with hyperdynamic septic shock. Crit Care Med 2010;38:579-587.

117 Hsiao HW, Tsai KL, Wang LF, Chen YH, Chiang PC, Chuang SM, et al: The decline of autophagy contributes to proximal tubular dysfunction during sepsis. Shock 2012;37: 289-296.

118 Good DW, George T, Watts BA 3rd: Tolllike receptor 2 mediates inhibition of $\mathrm{HCO}(3)(-)$ absorption by bacterial lipoprotein in medullary thick ascending limb. Am J Physiol Renal Physiol 2010;299:F536F544.

119 Schreiber A, Theilig F, Schweda F, Hocherl $\mathrm{K}$ : Acute endotoxemia in mice induces downregulation of megalin and cubilin in the kidney. Kidney Int 2012;82:53-59.

120 Bouchard J, Soroko SB, Chertow GM, Himmelfarb J, Ikizler TA, Paganini EP, et al: Fluid accumulation, survival and recovery of kidney function in critically ill patients with acute kidney injury. Kidney Int 2009;76: 422-427.

121 Anker SD, Egerer KR, Volk HD, Kox WJ, Poole-Wilson PA, Coats AJ: Elevated soluble CD14 receptors and altered cytokines in chronic heart failure. Am J Cardiol 1997;79: 1426-1430.

122 Peschel T, Schonauer M, Thiele H, Anker SD, Schuler G, Niebauer J: Invasive assessment of bacterial endotoxin and inflammatory cytokines in patients with acute heart failure. Eur J Heart Fail 2003;5:609-614.

123 Goncalves S, Pecoits-Filho R, Perreto S, Barberato SH, Stinghen AE, Lima EG, et al: Associations between renal function, volume status and endotoxaemia in chronic kidney disease patients. Nephrol Dial Transplant 2006;21:2788-2794.

124 Charalambous BM, Stephens RC, Feavers IM, Montgomery HE: Role of bacterial endotoxin in chronic heart failure: the gut of the matter. Shock 2007;28:15-23.

125 Opal SM, Laterre PF, Francois B, LaRosa SP, Angus DC, Mira JP, et al: Effect of eritoran, an antagonist of MD2-TLR4, on mortality in patients with severe sepsis: the ACCESS randomized trial. JAMA 2013;309:1154-1162.

126 Shoji H, Tani T, Hanasawa K, Kodama M: Extracorporeal endotoxin removal by polymyxin B immobilized fiber cartridge: designing and antiendotoxin efficacy in the clinical application. Ther Apher 1998;2:312.

127 Cruz DN, Perazella MA, Bellomo R, de Cal $\mathrm{M}$, Polanco N, Corradi V, et al: Effectiveness of polymyxin B-immobilized fiber column in sepsis: a systematic review. Crit Care 2007;11:R47.

128 Cruz DN, Antonelli M, Fumagalli R, Foltran F, Brienza N, Donati A, et al: Early use of polymyxin $\mathrm{B}$ hemoperfusion in abdominal septic shock: the EUPHAS randomized controlled trial. JAMA 2009;301:2445-2452.

129 Cutuli SL, Artigas A, Fumagalli R, Monti G, Ranieri VM, Ronco C, et al: Polymyxin-B hemoperfusion in septic patients: analysis of a multicenter registry. Ann Intensive Care 2016;6:77.

130 Klein DJ, Foster D, Schorr CA, Kazempour K, Walker PM, Dellinger RP: The EUPHRATES trial (Evaluating the Use of Polymyxin B Hemoperfusion in a Randomized controlled trial of Adults Treated for Endotoxemia and Septic shock): study protocol for a randomized controlled trial. Trials 2014;15: 218. 